\title{
A Pain in the Neck: Review of Cervicogenic Headache and Associated Disorders
}

\author{
Sanjay Yadla, MD², Jeffrey Gehret, MD1, Peter Campbell, MD², Steven Mandel, \\ MD', John K. Ratliff, MD² \\ 'Department of Neurology, Thomas Jefferson University, Philadelphia, PA \\ 2Department of Neurological Surgery, Thomas Jefferson University, Philadelphia, PA
}

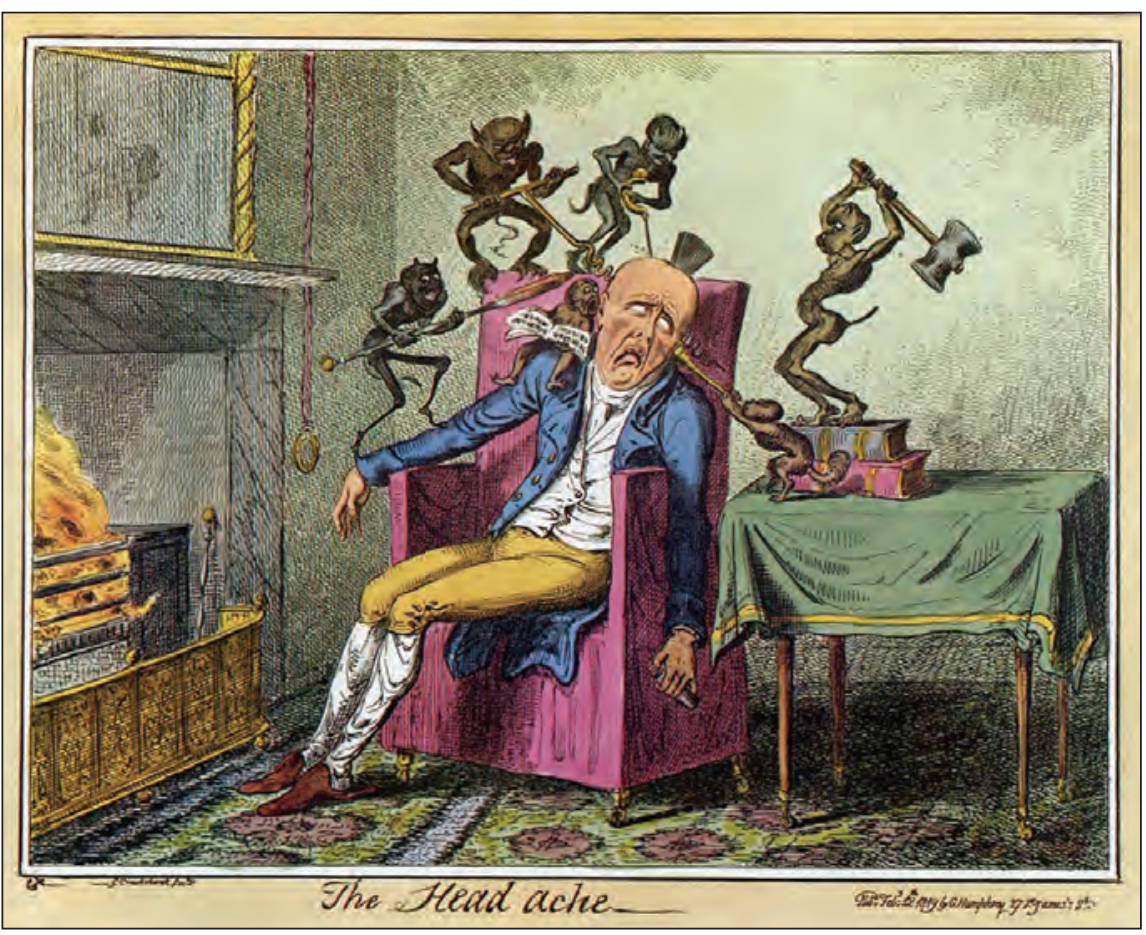

The Headache, color etching by George Cruikshank, c. 1830.

From National Library of Medicine, Bethesda, MD

\section{Introduction}

Cervicogenic headache describes pain referred to the head from a source in the cervical spine ${ }^{1}$. The diagnosis of this disorder is controversial. Some authorities believe that clinical criteria alone are sufficient while others, including the International Headache Society, require confirmatory tests to establish the diagnosis ${ }^{7}$. A multidisciplinary approach is often required to adequately manage this disorder. The purpose of the current review is to provide an overview of the diagnosis and treatment of cervicogenic headache. Further discussion focuses on associated disorders including whiplash, a common cause of cervicogenic headache.

\section{Cervicogenic Headaches}

Neck pain and tenderness are common symptoms present in many headache disorders. When cervical dysfunction or degenerative changes cause headache it is referred to as cervicogenic headache. Cervicogenic headache prevalence is estimated at $0.5 \%-4 \%$, but may be as high as $20 \%$ of patients presenting with severe chronic headaches. ${ }^{11,12,13}$ The mean age of patients with this condition is 43 years; the condition is more common in women. ${ }^{14}$
The International Headache Society defines diagnostic criteria for cervicogenic headache (Table 1). The most useful clinical features are pain that radiates from the neck to the frontotemporal region and pain that is reproduced with neck movements. ${ }^{15,16}$ The diagnostic criteria may help distinguish between cervicogenic headache and migraine symptoms, especially when a history of neck trauma is present. ${ }^{17}$

The most common source of cervicogenic headache is degenerative changes involving the upper cervical facet joints. ${ }^{1}$ While diagnostic imaging with magnetic resonance imaging (MRI), and computed tomography (CT) myelography can help support the diagnosis of cervicogenic headache, these radiographic studies are probably more useful in ruling out secondary causes of pain. ${ }^{18,19}$ Controlled diagnostic facet blocks using fluoroscopic guidance is one means to confirm the diagnosis of cervicogenic headache and possibly predict response to treatment modalities. ${ }^{20}$

There is no proven cure for cervicogenic headache. A comprehensive, multidisciplinary pain treatment program provides the greatest opportunity for overall clinical improvement. Pharmacologic treatments for chronic cervicogenic headache include medications that are used for the prevention or palliative management of neuropathic pain, such as tricyclic antidepressants, anticonvulsants, or other analgesics. Physical therapy may provide long-term improvement with a combination of manipulative and exercise therapy. Percutaneous radiofrequency neurotomy can be considered if diagnostic blockade is temporarily successful in providing complete pain relief. ${ }^{21}$ Lastly, there are reports of reduced headache frequency and intensity after surgical implantation of occipital or spinal nerve stimulators. $^{22}$

\section{Whiplash}

The term whiplash describes a constellation of symptoms and signs associated with bony or soft tissue injury occurring most commonly after a motor vehicle accident ${ }^{10}$. The Quebec Task Force (QTF) of whiplash associated disorders developed a classification system based on severity of signs and symptoms (Table 
Table 1: IHS diagnostic criteria for cervicogenic headache ${ }^{7}$

\begin{tabular}{|c|l|}
\hline Grade & Criteria \\
\hline A & $\begin{array}{l}\text { Pain referred from a source in the neck and felt in one or more regions of the head } \\
\text { and/or face, fulfilling criteria C and D }\end{array}$ \\
\hline B & $\begin{array}{l}\text { Clinical laboratory and/or imaging evidence of a disorder or lesion within the cervical } \\
\text { spine or soft tissues of the neck known to be, or generally accepted as a valid cause } \\
\text { of headache }\end{array}$ \\
\hline C & $\begin{array}{l}\text { Evidence that the pain can be attributed to the neck disorder or lesion based on at } \\
\text { least one of the following: 1) evidence of clinical signs that implicate a source of pain } \\
\text { in the neck, or abolition of headache after diagnostic blockade of a cervical structure } \\
\text { or its nerve supply with placebo or adequate controls }\end{array}$ \\
\hline D & $\begin{array}{l}\text { Pain resolves within 3 months after successful treatment of the causative disorder } \\
\text { or lesion }\end{array}$ \\
\hline
\end{tabular}

Table 2: QTF classification of whiplash-associated disorders ${ }^{8}$

\begin{tabular}{|c|l|}
\hline Grade & Classification \\
\hline 0 & $\begin{array}{l}\bullet \text { No complaint about the neck. } \\
\text { - No physical signs. }\end{array}$ \\
\hline I & $\begin{array}{l}\text { - Neck complaint of pain, stiffness or tenderness only. } \\
\text { - No physical signs. }\end{array}$ \\
\hline II & $\begin{array}{l}\text { - Neck complaint and musculoskeletal signs. } \\
\bullet \text { Musculoskeletal signs include decreased range of motion and point tenderness. }\end{array}$ \\
\hline III & $\begin{array}{l}\text { - Neck complaint and neurological signs. Neurological signs include decreased or } \\
\text { absent deep tendon reflexes, weakness and sensory deficits. }\end{array}$ \\
\hline IV & $\bullet$ Neck complain and fracture or dislocation. \\
\hline
\end{tabular}

2). In their critical review of the literature, the Neck Pain Task Force (NPTF) proposed that the QTF grading system be adapted to classify neck pain of any etiology including non-traumatic cervicalgia ${ }^{4}$. Whiplash remains a common cause of disability and is the most common injury associated with motor vehicle accidents, affecting up to $83 \%$ of victims ${ }^{3}$.

Current theories of the etiology of whiplash suggest that it occurs as a result of hyperextension of the lower cervical vertebrae in relation to a relative flexion of the upper cervical vertebrae $^{10}$. This type of abnormal motion may result from an acceleration-deceleration energy transfer to the spine that is typical of forces experienced by restrained passengers in motor vehicles that are 'rear-ended'.

Headaches may be present in 50 to $75 \%$ of acute whiplash sufferers ${ }^{6}$. Although the methodology of studies in this area make interpretation difficult, cervicogenic headaches appear to comprise a significant proportion of post-whiplash headache syndromes ${ }^{6}$. Treatment for whiplash in the absence of other pathology is primarily focused on physical therapy, self-mobilization, and return to normal activities as soon as possible. Recent studies suggest that early mobilization may lead to improved outcomes and that early motion restriction may have the opposite effect ${ }^{2}$. Treatment of whiplash injuries often presents a challenge to the clinician because of the complex interaction of psychosocial, physical, and legal factors amongst different patients ${ }^{2}$.

\section{Differential Diagnoses}

The multiple possible causes of suspected cervicogenic headache encompass a number of diseases requiring medical and/or surgical treatment. Chiari malformations, posterior fossa tumors, and vertebral or internal carotid artery dissections may all present with similar signs and symptoms as cervicogenic headache. Cervical spondylosis, herniated cervical intervertebral discs, spinal nerve compression, migraine and cluster headaches, and hemicrania continua are less serious causes of neck and head pain. A detailed history and physical by the informed clinician as well as proper imaging studies, when appropriate, can help to confirm or reject alternative diagnoses.

Chiari malformation is a downward displacement of the cerebellar vermis and tonsils through the foramen magnum. The brainstem, cranial nerves, and cerebellum may be compressed and symptoms related to the compression are common. Headaches may also occur in these patients. Chiari-associated headaches are classically protracted, suboccipital-occipital headaches of variable duration that are aggravated by Valsalva maneuvers, cough, or postural changes 5 . The headaches may be relieved with suboccipital decompression, although observational therapy is also often appropriate. Migraine and tension-type headaches occur in these patients as well but at a rate equal to the general population ${ }^{5}$.

Occipital neuralgia (Arnold's neuralgia) is paroxysmal pain in the distribution of the greater or lesser occipital nerves ${ }^{9}$. It may be associated with dysesthesia, hypesthesia, or tenderness in the affected area. It may be caused by muscle tension, muscle spasm, migraine headaches, or cranio-cervical junction disease. The pain may be unilateral or bilateral in distribution and the diagnosis can be confirmed by relief with local anesthetic block of the involved nerve.

\section{Conclusion}

Though the pathogenesis of cervicogenic headaches is relatively straightforward this disease presents several challenges to the practicing clinician. Even with established guidelines for diagnosis from several prominent specialty committees there is still some controversy on this topic. Although cervicogenic headache is a relatively common cause of chronic headache it is often misdiagnosed or unrecognized. Its differential is broad and includes diseases that can cause significant pathology if not diagnosed in a timely fashion. This requires the examiner to remain attentive to details in the history and physical and obtain appropriate imaging when necessary. With early diagnosis and management, physicians can help their patients significantly decrease the potential pain and disability associated with this challenging disorder.

\section{References}

1. Bogduk N, Govind J: Cervicogenic headache: an assessment of the evidence on clinical diagnosis, invasive tests, and treatment. Lancet Neurol 8:959-968, 2009 
2. Borchgrevink GE, Kaasa A, McDonagh D, Stiles TC, Haraldseth O, Lereim I: Acute treatment of whiplash neck sprain injuries. A randomized trial of treatment during the first 14 days after a car accident. Spine (Phila Pa 1976) 23:25-31, 1998

3. Cote P, Hogg-Johnson S, Cassidy JD, Carroll L, Frank JW, Bombardier C: Initial patterns of clinical care and recovery from whiplash injuries: a population-based cohort study. Arch Intern Med 165:2257-2263, 2005

4. Nordin M, Carragee EJ, Hogg-Johnson S, Weiner SS, Hurwitz EL, Peloso PM, et al: Assessment of neck pain and its associated disorders: results of the Bone and Joint Decade 2000-2010 Task Force on Neck Pain and Its Associated Disorders. Spine (Phila Pa 1976) 33:S101-122, 2008

5. Pascual J, Oterino A, Berciano J: Headache in type I Chiari malformation. Neurology 42:1519-1521, 1992

6. Sjaastad O, Fredriksen T, Bakketeig L: Headache subsequent to whiplash. Curr Pain Headache Rep 13:52-58, 2009

7. International Headache Society. The International Classification of Headache Disorders: 2nd edition. Cephalalgia 24 Suppl 1:9-160, 2004

8. Spitzer WO, Skovron ML, Salmi LR, Cassidy JD, Duranceau I, Suissa S, et al: Scientific monograph of the Quebec Task Force on Whiplash-Associated Disorders: redefining "whiplash" and its management. Spine (Phila Pa 1976) 20:1S-73S, 1995

9. Ward JB: Greater occipital nerve block. Semin Neurol 23:59-62, 2003

10. Yadla S, Ratliff JK, Harrop JS: Whiplash: diagnosis, treatment, and associated injuries. Curr Rev Musculoskelet Med 1:65-68, 2008

11. Evers S. Comparison of cervicogenic headache with migraine. Cephalgia 28 Suppl 1: 16-17, 2008

12. Sjaatstad O, Cervicogenic Headache: comparison with migraine without aura; Vaga study. Cephalgia 28 Suppl 1 $18-20,2008$

13. Haldeman S, Dagenais S. Cervicogenic headaches; a critical review. Spine J 1. 31-46, 2001

14. van Suijlekom HA, Lame I, Stomp-van den Berg SG, kessels AG, Weber WE. Quality of life of patients with cervicogeni headache: a comparison with control subjestcs and patients with migraine or tension-type headache. Headache 43: 1034-1041, 2003

15. van Suijlekom HA, de Vet HCW, Stomp-van den Berg SG, Weber WE. Interobserver reliability of diagnostic criteria for cervicogenic headache. Cephalgia 19: 817-823, 1999

16. van Suijlekom HA, de Vet HCW, Stomp-van den Berg SG, Weber WE. Interobserver reliability in physical examination of the cervical spine in patients with headache. Headache 40: $581-86,2000$

17. Antonaci F, Ghirmai S, Bono S, Sandrini G, Nappi G. Cervicogenic headache: evaluation of the original diagnostic criteria. Cephalgia 21: 573-82, 2001

18. Fredriksen TA, Fougner R, tangerud A, Staastad O. Cervicogenic headache; radiological investigations concerning headache. Cephalgia 9: 139-146, 1989

19. Pfaffenrath V, Dandekar R, Pollmann W. Cervicogenic headache, the clinical picture, radiological findings and hypotheses on its pathophysiology. Headache 27: 495-99, 1987

20. Pikus HJ, Phillips JM. Characteristics of patients successfully treated for cervicogenic headache by surgical decompression of the second cervical root. Headache 35: 621-29, 1995

21. Blume HG. Cevicogenic headaches: radiofrequency neurotomy and the cervical disc and fusion. Clin Exp Rheumatol 18 Suppl 19: 53-58, 2000

22. Popeney Ca, Alo KM. Peripheral neurostimulation for the treatment of chronic, disabling trasformed migraine. Headache 43: 369-375, 2003
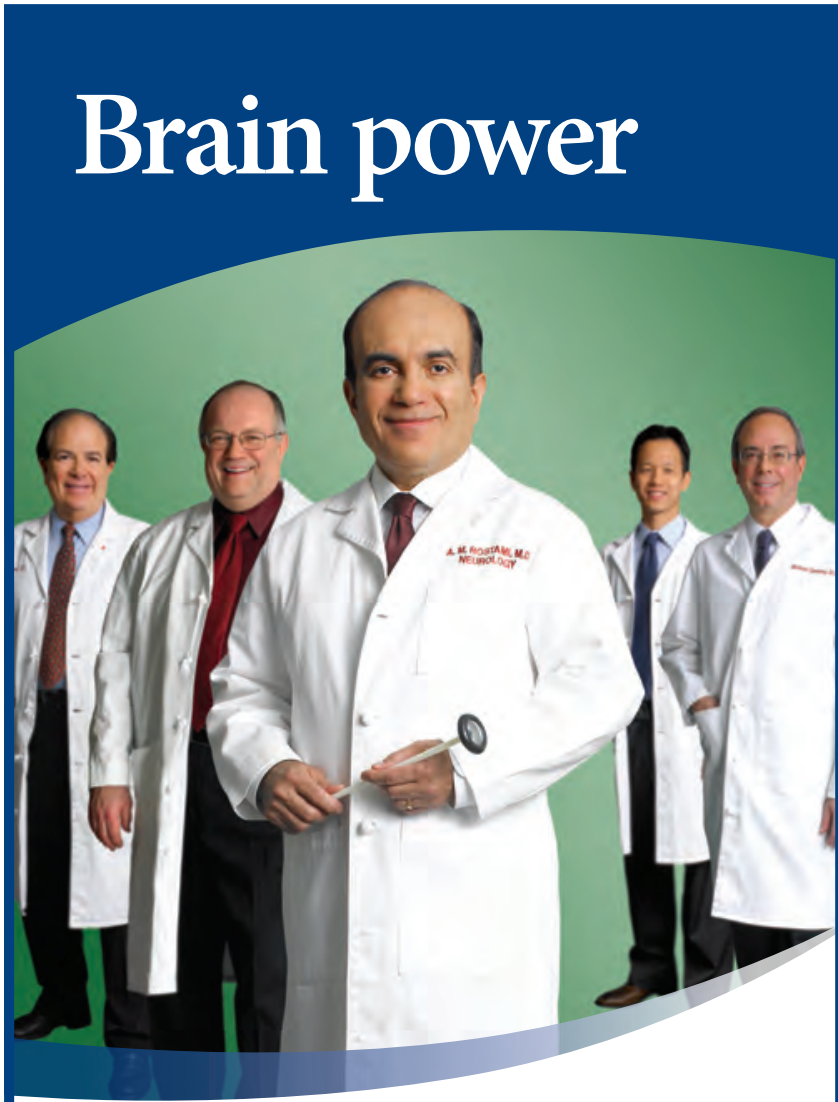

Jefferson neurologists have pioneered new treatments for stroke, and are on the leading edge in developing new treatments for everything from multiple sclerosis and Parkinson's disease to epilepsy and headache as well as other nerve and muscle diseases. Some are officers in prestigious national medical societies. Many are well-known in the worldwide medical community. Best of all, they work in our communityso they're available to see you.

The region's only hospital with an experienced, specialized staff dedicated to neuroscience.

Most insurance plans accepted, including Medicare.

Jefferson.

Hospital for Neuroscience

- Thomas Jefferson University Hospital

- Jefferson Hospital for Neuroscience

- Methodist Hospital 